\title{
A Study on Public Safety Environment in Open Blocks
}

\author{
Yuxi Weng* \\ Shanghai University, Shang Hai Academy of Fine Arts, 149 Yanchang Road, Jing'an District, \\ Shanghai
}

\begin{abstract}
It has been five years since the block system was put forward. Up to now, there are three open blocks in Shanghai. At the beginning of "block system", the security of open block was controversial. This research investigates two groups of open blocks and closed blocks through questionnaires and interviews. It analyses the public security environment of open blocks from two aspects of objective public security environment problems and subjective residents' safety psychological feelings, which leads to the thinking of "block system" public security environment.
\end{abstract}

\section{Introduction}

On February 21, 2016, "several opinions of the CPC Central Committee and the State Council on Further Strengthening the management of urban planning and construction" put forward that "the block system should be promoted for new residential buildings, and in principle, closed residential areas will not be built any more." The opinions mentioned in detail that the completed residential quarters and unit compound should be opened step by step to realize the publicity of internal roads, solve the problem of traffic network layout, and promote the economical use of land. In addition, the urban road layout concept of "narrow road and dense road network" should be established, and the road network system with reasonable gradation of expressway, main and secondary trunk roads and branch roads should be built.

It has been five years since the block system was put forward. At the beginning of its proposal, it was controversial, and the first one was the security of the community. What people are worried about is how to ensure the personal safety of residents in the community and how to ensure the property safety of residents in the community. According to statistics, $30 \%$ of netizens think that various security risks will occur after the closed community becomes an open block. The mainstream media's point of view is that the open block is safer than the closed community, because with the increase of the city's bottom business with the publicity of the road, every shop unconsciously plays the role of "sunrise masses". The owners of these shops are familiar with every resident living nearby. Whenever a stranger comes here, they are the first to be alert and alert. These shops generally have long business hours, and their role is 100 times stronger than that of the security of the closed community.

* Corresponding author: 1193702549@qq.com 
In a word, there are different opinions on the safety of open blocks. Today, two years after the "block system" was put forward, it is easier to explore its essence through the phenomenon. The purpose of this research is to analyse the public security environment of open blocks by comparing the security feelings of residents in open and closed blocks.

\section{Analysis and investigation of investigation contents}

\subsection{General situation of public safety environment in residential area}

According to the statistics of relevant departments of the state, the urban public areas of our country are mainly threatened by the following public security, social safety accidents, man-made accident disasters, public health safety problems and other natural disasters. There are many reasons for the above public safety problems, mainly in the natural environment, as well as socio-economic development factors and urban planning, architectural design and other reasons. For a more special public area such as residential areas, its safety problems are mostly theft, fire and traffic safety issues, that is, community security, traffic and fire safety issues.

\subsection{Security issues arising from the public environment of open blocks}

By interviewing the staff and residents of the open and closed neighbourhoods respectively, we can conclude that the open blocks are different from the security, traffic and fire safety problems and hidden dangers arising from the closed neighbourhoods.

\subsubsection{Security issues.}

Block system community is different from closed community, there is no blocking of the community wall, more social groups can freely enter and leave the residential area, the flow of fish and dragon mixed, which will also be the community's public security management pressure scattered into the residential buildings. Although there is a view that the ground floor shops for the community to increase popularity, at the same time can be used as a "sunrise masses", monitoring everything near the residential building, but the author believes that "security" is not the inherent responsibility of shops. Shop assistants are responsible for receiving customers most of the business hours, have no time to pay attention to the situation around the house, and come and go customers more easily become illegal. The public security management of the community has become decentralized from centralization, and the pressure of management will only be strengthened and will not be alleviated. This means that a block can be created that gives residents a full sense of security.

\subsubsection{Traffic safety issues.}

With the publication of the roads inside the community, the road downstairs of the residential building has been more widely used, and the road traffic has become more complex, which also brings some traffic safety hazards for residents to travel. Out of the residential buildings, directly facing the city road, which mainly affects the daily life of the elderly group. In the past, for safety reasons, the daily activities of the elderly population were generally in the small areas in which they lived, and the publication of roads made it necessary for the elderly population to travel through more dangerous urban roads. The 
traffic problem brought about by the publication of internal roads lies really in the residents' psychological feeling of safety, not in the essence of the problems they will really cause.

\subsubsection{Fire safety issues.}

One of the characteristics of the block system is the large number of residential bottom merchants. And because of the store's cargo stacking and other behavior, the residential building with the bottom dealer than the general residential building will have a greater fire safety hazard, which is also one of the major public safety environmental problems can not be ignored.

\section{Based on the SD method analysis of the residents' psychological feelings of safety}

\subsection{Sample selection}

The author divides the public space in the residential area into three categories according to the behavior of the residents, namely, the road traffic space, the public space for the residents' activities and the relatively private inside space of the corridor. The road traffic space, public activity space and the interior space of the corridor in the four residential areas were used as a sample for the study.

\subsection{Selection of adjectives and evaluation scales}

In addition, the prerequisite for the SD survey is the selection of adjectives and evaluation scales to be used for psychological evaluation. Here the author chooses the adjective pair as "safety-danger" and the evaluation factor as "security". In this respect, the five-level evaluation scale is used, that is, the score is set to $-2,-1,0,1,2$, with 0 as the center axis symmetry setting.

\subsection{The choice of the respondents to the SD questionnaire}

The survey surveyed a total of 60 people, 15 people in each residential area. The respondents were 10 to 19 years old, 13 people aged 20 to 29,18 persons aged 30 to 39,11 persons aged 40 to 49,10 persons aged 50 to 59 years and 8 persons aged 60 and over. The basic distribution is positive and too wide, which is of universal significance.

\subsection{Comprehensive safety psychological evaluation}

After collecting 60 sets of SD questionnaire, the average score of safety psychological feeling of 12 spatial samples was obtained by using Excel software, and the average score was calculated according to the results.

Find out the mean value of the sense of security score of the same kind of space samples in different residential areas and get the comprehensive psychological feeling score of residents in residential areas, as shown in Figure 1. It can be seen that the more private space in the public space of residential areas gives residents a higher sense of security. 


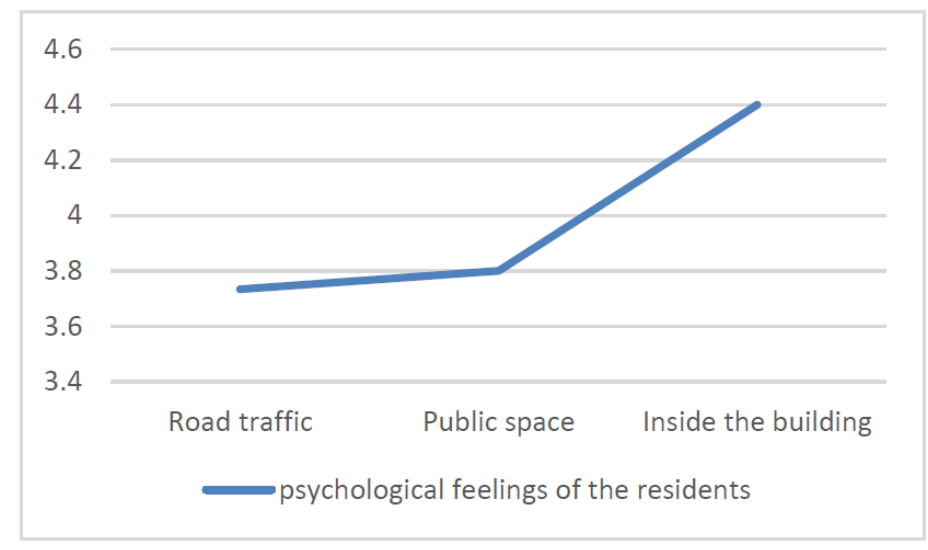

Fig. 1. Comprehensive evaluation of residents' psychological feeling of safety.

\subsection{The psychological feeling score of open block and closed neighborhood is compared}

Figure 2 provides an intuitive view of the security score lines of the two gated communities, which are basically higher than the other two open blocks. The comparison of the psychological feeling of open block and closed community security can be seen.

However, the road traffic safety score for the Open Block I is higher than the road traffic safety score for Gated Community I. The author thinks that because Gated Community I belongs to the old-fashioned community has no underground parking lot, the ground road is narrow and has to bear a large number of ground parking, road traffic to the residents of the safety feeling is low. The Open Block I is actually a "semi-open" community, not completely open, some internal roads are not public.

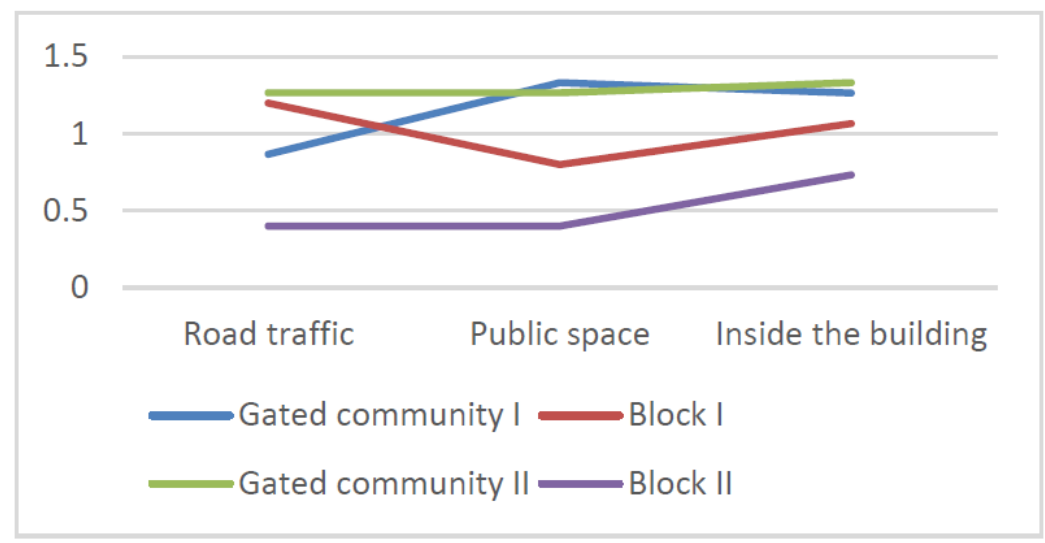

Fig. 2. The psychological feelings of the residents of each community are graded.

\subsection{Summary}

In general, whether from an objective point of view or from a subjective point of view, open blocks are indeed not as safe as closed neighbourhoods, but security is not a non-black or white concept, "not as good as closed community security" is not to say that living in 
open blocks is dangerous, from the above data and tables can be seen that the safety of residents in open blocks is still positive, open blocks and closed neighbourhoods between the degree of security difference is not huge, This gap can be made up by strengthening the public security management of the community.

\section{Conclusion}

Block system can indeed alleviate or even solve a range of urban problems, such as saving urban land, making urban transport networks more complete, and promoting real estate. But while solving the big problem of the city, some small living problems have been added to the residents. At the same time that the government formulates policies, it should gradually issue relevant opinions with it, and should also coordinate the balance between the living environment of urban residents and the urban environment.

As far as the public safety environmental problems of open blocks are concerned, the opening of the community is bound to introduce some security risks, but it is entirely through the strengthening of management, advanced security equipment input and residents' safety awareness to solve these small problems, after all, the implementation of the "block system" is also fundamentally to improve the large living environment of the city as a unit. Not to mention the essence of security is the people themselves, when the quality of the people of the whole city improves, no one violates the law, there is no lawless, such a city how to talk about insecurity? By then, do not say open community, even if the night does not close, the sense of security is still full of good living environment.

\section{Acknowledgment}

The research was kindly funded by the National Natural Science Foundation of China (No: 51808330)

\section{References}

[1] Mei Yang, Chunxiang Chen: Discussion on public safety environment of residential area, Science and Technology Research, 2014

[2] Kaiguang Jiang: Study on landscape evaluation system of residential area based on SD method -- a case study of Hefei City, Master's thesis, 2012.04

[3] Rui Wang, Qianhua Zhong: Security investigation and network security system design of open blocks in Nanjing, Reform and Opening Up, 2018.01

[4] Yan Ma: On the planning and transformation of "open block", Housing and Real Estate, 2018.01

[5] Xiaoyan Ma, Lin Qi: On the opening and closing of the open block system, Science and technology economy guide, 2017.10 